\title{
BMJ Open Prevalence and determinants of serological evidence of atrophic gastritis among Arab and Jewish residents of Jerusalem: a cross-sectional study
}

\author{
Khitam Muhsen, ${ }^{1}$ Ronit Sinnreich, ${ }^{2}$ Dafna Merom, ${ }^{3}$ Gany Beer-Davidson, \\ Hisham Nassar, ${ }^{4}$ Dani Cohen, ${ }^{1}$ Jeremy D Kark ${ }^{2}$
}

To cite: Muhsen K, Sinnreich R, Merom D, et al. Prevalence and determinants of serological evidence of atrophic gastritis among Arab and Jewish residents of Jerusalem: a crosssectional study. BMJ Open 2019;9:e024689. doi:10.1136/ bmjopen-2018-024689

- Prepublication history and additional material for this paper are available online. To view these files, please visit the journal online (http://dx.doi. org/10.1136/bmjopen-2018024689).

DC and JDK contributed equally.

Received 11 June 2018 Revised 19 0ctober 2018 Accepted 12 December 2018

Check for updates

(c) Author(s) (or their employer(s)) 2019. Re-use permitted under CC BY-NC. No commercial re-use. See rights and permissions. Published by BMJ.

For numbered affiliations see end of article.

Correspondence to Dr Khitam Muhsen; kmuhsen@post.tau.ac.il

\section{ABSTRACT}

Objective Understanding the correlates of premalignant gastric lesions is essential for gastric cancer prevention. We examined the prevalence and correlates of serological evidence of atrophic gastritis, a premalignant gastric condition, using serum pepsinogens (PGs) in two populations with differing trends in gastric cancer incidence.

Methods In a cross-sectional study, using ELISA we measured serum PGI and PGIl concentrations (Biohit, Finland), Helicobacter pylori serum IgG and cytotoxinassociated gene $\mathrm{A}(\mathrm{CagA})$ antigen IgG antibodies in archived sera of 692 Jews and 952 Arabs aged 25-78 years, randomly selected from Israel's population registry in age-sex and population strata. Multivariable logistic regression analyses were performed.

Results Using cut-offs of $\mathrm{PGl}<30 \mu \mathrm{g} / \mathrm{L}$ or PGI:PGIl $<3.0$, the prevalence of atrophic gastritis was higher among Arab than Jewish participants: $8.8 \%$ (95\% Cls $7.2 \%$ to $10.8 \%$ ) vs $5.9 \%$ (95\% Cl $4.4 \%$ to $7.9 \%$ ), increasing with age in both groups $(\mathrm{p}<0.001$ for trend). Among Jewish participants, infection with $H$. pylori CagA phenotype was positively related to atrophic gastritis: adjusted $O R$ (aOR) 2.16 (95\% Cl 0.94 to 4.97), but not to non-CagA infections aOR 1.17 (95\% Cl 0.53 to 2.55$)$. The opposite was found among Arabs: aOR $0.09(95 \% \mathrm{Cl} 0.03$ to 0.24$)$ for CagA positive and aOR $0.15(95 \% \mathrm{Cl} 0.06$ to 0.41$)$ for Cag A negative phenotypes ( $p<0.001$ for interaction). Women had a higher atrophic gastritis prevalence than men. Obesity and smoking were not significantly related to atrophic gastritis; physical activity tended to be inversely associated in Arabs ( $p=0.08$ for interaction).

Conclusions The prevalence of atrophic gastritis was higher among Arabs than Jews and was differently associated with the CagA phenotype.

\section{INTRODUCTION}

Gastric cancer, among the most common cancers, is a leading cause of cancer deaths worldwide. ${ }^{1}$ Gastric cancer incidence rates are highest in East Asia, followed by Central/ East Europe and South America, with low rates in North America and Africa, ${ }^{1}$ as well as in Israel. $^{2}$ Gastric cancer is classified
Strengths and limitations of this study

- A strength of the study is the large general population sample consisting of 1644 participants.

- The sample included representation of various age groups (25-78 years), both sexes and various ethnic groups, thus providing findings of broad generalisability.

- A possible limitation is the cross-sectional study design, which limits the ability to assess directionality in the associations of lifestyle variables with atrophic gastritis.

- Using serum pepsinogens to study atrophic gastritis likely underestimated the prevalence of this outcome.

according to subsite; cardia (proximal) cancer that originates in the area near the oesophageal-gastric junction and non-cardia (distal) gastric cancer, which comprises $~ 73 \%$ of the cases globally. ${ }^{3}$ Helicobacter pylori is an established cause of distal gastric cancer (almost 90\%). ${ }^{4}$ Infection with $H$. pylori strains expressing cytotoxin-associated gene A (CagA) antigen is associated with greater risk for gastric cancer. ${ }^{5}$

Gastric cancer develops in a progressive manner known as the Correa cascade. This process is initiated and promulgated by $H$. pylori, starting with chronic active gastritis that progresses to chronic atrophic gastritis, intestinal metaplasia and dysplasia that finally develops into invasive carcinoma. ${ }^{67}$ Hence, the identification of risk factors for atrophic gastritis, a precursor of gastric cancer, is essential for gastric cancer prevention. In studies of the general asymptomatic population, non-invasive markers are needed to identify patients at risk. Serum pepsinogen I (PGI) and PGII, proenzymes of pepsin, are most commonly used. PGs are secreted into the gastric lumen and can be found in the 
serum. ${ }^{8}$ With increasing severity of $H$. pylori gastritis, serum PGI and PGII levels become elevated, but when atrophic changes occur in the corpus, the PGI level and the PGI:PGII ratio decrease. These markers can predict atrophic gastritis, intestinal metaplasia and gastric cancer. $^{710-13}$

In Israel, the incidence of gastric cancer was higher among the Jewish population than the Arab population, although the prevalence of $H$. pylori infection is higher in the latter. ${ }^{14}$ Recently, the gap in incidence of gastric cancer has closed, due to decreased rates in the Jewish population, but slightly increased rates in the Arab population. $^{2}$ In this unique setting, we examined the prevalence of serological evidence of atrophic gastritis, using serum PG levels as non-invasive markers for this condition, in Arab and Jewish residents of Jerusalem, as well as potential risk factors. Our hypothesis was that demographic factors, lifestyle and $H$. pylori infection are related to atrophic gastritis seroprevalence.

\section{METHODS}

\section{Study design and population}

We used archived anonymised sera obtained in the framework of a cross-sectional study conducted in 2007-2008 among Jewish and Arab residents of Jerusalem, aged 25-78 years at the examination. Details of the study design have been reported. ${ }^{15} 16$ Briefly, age-stratified and sex-stratified random samples of 2000 Arab residents of East Jerusalem and 2000 Israeli Jewish residents of Jerusalem, aged 25-74 years at sampling, were drawn from the Israel national population registry. Individuals were ineligible if they were unable to provide informed consent, institutionalised, housebound or had a severe illness; and women, if they were pregnant or gave birth within the 3 months preceding study initiation. The response rates among those located were $77 \%$ for Arabs $(n=970)$ and $54 \%$ for Jews $(\mathrm{n}=712) .{ }^{15} 16$ Sera from $952(98.0 \%)$ and 692 $(97.2 \%)$ Arab and Jewish participants, respectively, were available for this study.

Data were collected through personal interviews with the participants. Information was obtained on age (grouped as 25-44, 45-64 and 65-78 years); sex and education (classified as having an academic degree, high school/some college, some high school or less). For Jewish participants, country of birth was defined based on the participant's report of a country of birth, which was classified as Israel, Europe, Asia (predominantly the Middle East), North Africa and the Americas. Smoking was classified as reported smoking of at least one cigarette daily versus no smoking/other (ie, smoking less than one cigarette/day). Height and weight were measured without shoes and with light clothing. Weight in kilograms was measured to the nearest $100 \mathrm{~g}$ using a Visual Analogue Scale, and standing height was measured to the nearest $0.1 \mathrm{~cm}$. Body mass index (BMI) was calculated as: weight (in $\mathrm{kg}$ )/height (in metres ${ }^{2}$ ). Obesity was defined as BMI $\geq 30 \mathrm{~kg} / \mathrm{m}^{2}$. Physical activity in a typical week was assessed using the Multi-Ethnic Study of Atherosclerosis questionnaire. ${ }^{15}$ Participants were classified as physically active if they met WHO recommendation for physical activity in adults aged $18-64$ years ${ }^{17}$ : doing at least $150 \mathrm{~min}$ of moderate-intensity aerobic physical activity throughout the week or doing at least $75 \mathrm{~min}$ of vigorous-intensity aerobic physical activity, or an equivalent combination of moderate and vigorous-intensity physical activity of at least 600 metabolic equivalent of task (MET)-minutes weekly.

\section{Laboratory methods}

Concentrations of serum PGI and PGII were quantified by ELISA (Biohit, Helsinki, Finland) and PGI:PGII ratios were calculated. Atrophic gastritis was defined as a serum PGI level of $<30 \mu \mathrm{g} / \mathrm{L}$ or a PGI:PGII ratio $<3.0$, following the manufacturer's instructions. Sera were also tested for the presence of specific H. pylori IgG antibodies using ELISA (Enzygnost Anti-H. pylori II/IgG kit, Siemens Diagnostics Product, Marburg, Germany). The sensitivity and specificity of the kit are 94\%-98\%. The presence of IgG antibody against recombinant CagA protein was measured in $H$. pylori-positive duplicate sera using a modified in-house ELISA protocol as previously described. ${ }^{18}$ All assays were performed in one laboratory at Tel University by an experienced technician. Each ELISA plate included sera from both Arab and Jewish participants, in addition to positive and negative controls and calibrators that were provided in the kits. Repeated tests of subsamples PGI $(n=26)$ and PGII $(n=16)$ on two different occasions showed high correlations between the two measurements: Pearson correlation coefficients were 0.98 and 0.97 , respectively.

\section{Patient and public involvement}

Patients and public figures were not involved in the study design or implementation.

\section{Statistical analysis}

$\chi^{2}$ tests were employed to assess unadjusted associations of sociodemographic variables, $H$. pylori serostatus, obesity, physical activity and smoking with atrophic gastritis $($ PGI $<30 \mu \mathrm{g} / \mathrm{L}$ or a PGI:PGII ratio $<3.0$ ). Bivariate and multivariable logistic regression models were fitted. Unadjusted and adjusted ORs (aORs) and 95\% CIs were obtained from logistic regression models. Pooled and stratified analyses by population group were conducted. Interactions between population groups and other independent variables were assessed. We assessed differences in the mean PGI:PGII ratio according to $H$. pylori serostatus, using age-adjusted and sex-adjusted mixed linear models. Overall, missing information was very low (up to $0.6 \%$ for smoking); therefore, the imputation of data was not performed. Sensitivity analysis was performed using the following definitions: (1) PGI $<40 \mu \mathrm{g} / \mathrm{L}$ or PGI:PGII $<3$; (2) PGI $<50 \mu \mathrm{g} / \mathrm{L}$ or PGI: PGII $<3$. These cut-off values were selected based on a systematic review that assessed the validity of the Biohit ELISA ${ }^{12}$; most studies were 
shown to use a PGI:PGII ratio $<3$; and in some, this was in combination with PGI levels that were mostly in the range of 25-50 $\mathrm{gg} / \mathrm{L}$. Data were analysed using SPSS V.24.

\section{RESULTS}

The mean ages of the Jewish and Arab participants were 52.5 years (SD 13.5) and 52.0 years (SD 13.8), respectively $(\mathrm{p}=0.4)$. Men comprised $52.7 \%$ and $53.0 \%$ of the Jewish and Arab participants, respectively $(\mathrm{p}=0.9)$. The prevalence of atrophic gastritis was $7.6 \%$ (95\% CI $6.4 \%$ to 9.0\%) and was more common among Arab participants: $8.8 \%$ (95\% CI $7.2 \%$ to $10.8 \%$ ) than among Jewish participants: $5.9 \%$ (95\% CI $4.4 \%$ to $7.9 \%$ ), $\mathrm{p}=0.029$.

\section{Risk factors for atrophic gastritis}

The prevalence of atrophic gastritis was higher in women than in men $(9.3 \%$ and $6.1 \%$, respectively, $\mathrm{p}=0.014)$ and increased strongly with age, from $2.6 \%$ in those aged 25-44 years to $11.5 \%$ in those aged $65-78$ years ( $p$ for trend $<0.001$ ). Unexpectedly, participants who were seronegative for $H$. pylori IgG antibody had a higher prevalence of atrophic gastritis (11.8\%) compared with those who were $H$. pylori seropositive, both among those who were negative and positive for CagA IgG serum antibody ( $5.6 \%$ and $7.0 \%$, respectively) $(\mathrm{p}=0.001)$. Physically active persons had a lower prevalence of atrophic gastritis than non-active participants $(7.0 \%$ vs $11.3 \%, \mathrm{p}=0.017)$. Smokers displayed a borderline significant lower prevalence of atrophy than non-smokers $(5.6 \%$ vs $8.3 \%, \mathrm{p}=0.086)$. No significant differences in atrophic gastritis prevalence were found according to education and obesity (table 1 ).

A strong interaction was found between population group and $H$. pylori serostatus ( $\mathrm{p}$ for interaction $<0.001$ ). An interaction term between population group and physical activity was statistically significant $(\mathrm{p}=0.034)$ (table 1), but not for the other independent variables. Among Jewish participants, the prevalence of atrophic gastritis was $9.4 \%$ in persons infected with CagA positive strains, followed by $5.6 \%$ in persons infected with strains lacking CagA and $4.5 \%$ in H. pylori seronegatives ( $\mathrm{p}$ for trend=0.061). However, among Arab participants, individuals who were seronegative for $H$. pylori IgG antibody had a substantially higher prevalence of atrophic gastritis (24.1\%) compared with $H$. pylori seropositives, regardless as to whether they were negative or positive for CagA IgG antibody: $5.7 \%$ and $6.0 \%$, respectively, $(\mathrm{p}<0.001)$. Among Arabs, physically active persons had a lower prevalence of atrophic gastric than non-active ones $(7.4 \%$ vs $14.8 \%$, $\mathrm{p}=0.002$ ), whereas Jewish participants showed no significant difference according to physical activity. In both population groups, no significant differences were found in the prevalence of atrophic gastritis according to education, smoking and obesity (table 1). Among Jewish participants, atrophic gastritis prevalence was lower in persons who were born in Israel and the Americas (3.9\%-4.5\%) compared with those who were born in European, African or Asian countries $(7 \%-12 \%), \mathrm{p}=0.058(\mathrm{df}=4)$ (table 1$)$.
In multivariable models, the association of age with atrophic gastritis persisted in both Jews (table 2) and Arabs (table 3), but the association with sex was not significant. Jewish participants who were positive for CagA IgG antibody had a higher likelihood of atrophic gastritis than did uninfected ones: aOR 2.16 (95\% CI 0.94 to 4.97), $\mathrm{p}=0.065$ (table 2). In Arabs, however, inverse associations were observed for both CagA positive and negative phenotypes with atrophic gastritis (table 3 ). The associations of physical activity and smoking with atrophic gastritis were not significant among Jewish participants (table 2).

Among Arabs no significant association was found between smoking and atrophic gastritis $(\mathrm{p}=0.6)$; whereas, an inverse association was found with physical activity: aOR 0.63 ( $95 \%$ CI 0.36 to 1.09 ) ( $\mathrm{p}=0.08$ for interaction) (table 3). A protective effect of physical activity among Arabs appeared to be limited to non-smokers: aOR 0.52 (95\% CI 0.28 to 0.94$)$ ( $\mathrm{p}=0.029)$, but a test for a smokingphysical activity interaction was not significant $(\mathrm{p}=0.11)$.

In population-pooled multivariable analysis, a significant interaction was found between population group and $H$. pylori infection. Specifically, $H$. pylori seronegative Arabs had a substantially higher likelihood of atrophic gastritis than both CagA seropositives (aOR 0.09, 95\% CI 0.033 to 0.25 ) and seronegatives (aOR $0.15,95 \%$ CI 0.06 to 0.41 ), with associations opposite those evident in their Jewish counterparts $(\mathrm{p}<0.001$ for interaction) (table 4). In this model, CagA IgG seroprevalence was related to a twofold higher likelihood of atrophic gastritis among Jews. No significant associations were found of smoking and physical activity with atrophic gastritis. An additional model that included an interaction term between physical activity and population group suggested an inverse association with physical activity among Arabs only $(\mathrm{p}=0.08)$ (data not shown).

Given the divergent associations between $H$. pylori serostatus and atrophic gastritis in the Arab and Jewish samples, we explored whether $H$. pylori CagA seroprevalence is related to lower mean PGI:PGII. A linear mixed model that adjusted for age and sex showed that in both population groups, persons with CagA IgG serum antibody had the lowest mean PGI:PGII ratio, followed by persons who were $H$. pylori seropositive but lacking CagA antibody and lastly by those uninfected with $H$. pylori (p for trend $<0.001$ in both groups). However, the slope of the ordinal trend was weaker among the Arabs, and Jewish participants with CagA phenotype had a lower mean PGI:PGII ratio than their Arab counterparts, and those seronegative for $H$. pylori had higher PGI: PGII ratios (figure 1 ).

\section{Sensitivity analysis}

Based on a systematic review that assessed the validity of Biohit ELISA, ${ }^{12}$ most studies used a PGI:PGII ratio $<3$; and in some, this was in combination with PGI levels in the range of $25-50 \mu \mathrm{g} / \mathrm{L}$. Therefore, in the sensitivity analysis, we used the following definitions for atrophic gastritis: (1) PGI $<40 \mu \mathrm{g} / \mathrm{L}$ or PGI:PGII $<3$; (2) PGI $<50 \mu \mathrm{g} / \mathrm{L}$ or 
Table 1 Prevalence of atrophic gastritis according to sociodemographic factors and health behaviours

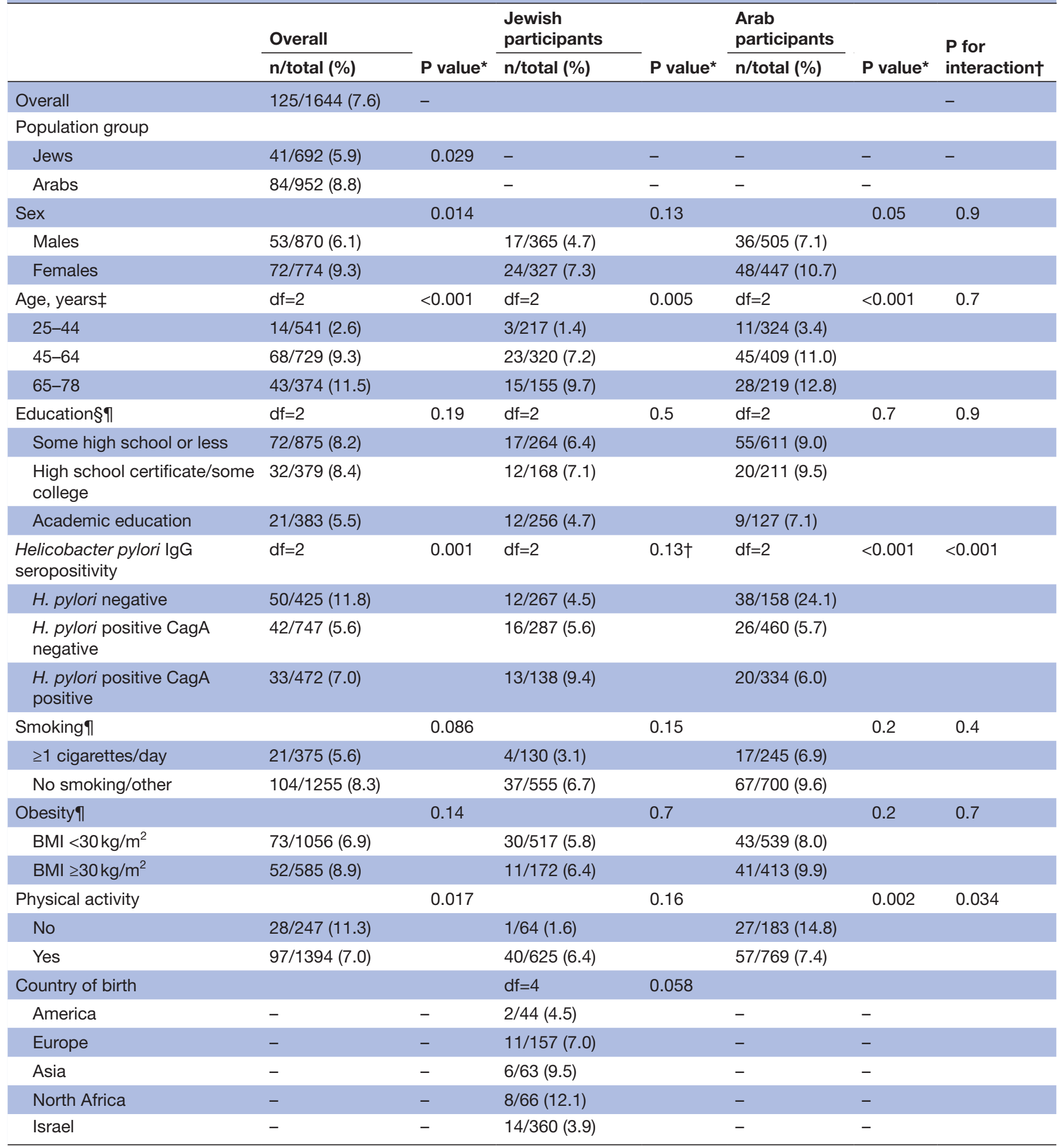

${ }^{*} \mathrm{P}$ values by $\chi^{2}$ test or Fisher exact test where appropriate.

†P for interaction between population group and each of the independent variables, obtained by logistic regression models.

$\ddagger \mathrm{P}$ for trend $0.001,<0.001$ and $<0.001$ among Jewish participants, Arab participants and overall.

$\S \mathrm{P}$ for trend $0.4,0.6$ and 0.12 among Jewish participants, Arab participants and overall.

ๆOverall information on education, smoking, BMI was missing for 7, 10 and 3 persons, respectively.

$\mathrm{BMI}$, body mass index; CagA, cytotoxin-associated gene A.

PGI:PGII $<3$. The overall prevalences of atrophic gastritis were $7.8 \%$ and $9.3 \%$ when applying these definitions, respectively. The respective prevalences among Jewish versus Arab participants were $6.1 \%$ vs $9.0 \% \quad(\mathrm{p}=0.028)$ and $7.2 \%$ vs $10.7 \%(\mathrm{p}=0.016)$. Multivariable models using these definitions (online supplementary table 1 ) showed 


\begin{tabular}{|c|c|c|c|c|}
\hline Variable & Crude OR $(95 \% \mathrm{Cl})^{*}$ & P value* & Adjusted OR $(95 \% \mathrm{Cl}) \dagger$ & $\mathbf{P}$ value \\
\hline \multicolumn{5}{|l|}{ Sex } \\
\hline Males & Reference & & Reference & \\
\hline Females & 1.62 (0.85 to 3.07$)$ & 0.13 & 1.43 (0.74 to 2.77$)$ & 0.27 \\
\hline Age, years & $d f=2$ & 0.007 & $d f=2$ & 0.01 \\
\hline $25-44$ & Reference & & Reference & \\
\hline $45-64$ & 5.52 (1.64 to 18.64$)$ & 0.006 & $4.99(1.47$ to 16.95$)$ & 0.01 \\
\hline $65-78$ & 7.64 (2.17 to 26.88$)$ & 0.002 & $7.14(2.00$ to 25.41$)$ & 0.002 \\
\hline $\begin{array}{l}\text { Helicobacter pylori lgG } \\
\text { seropositivity }\end{array}$ & $d f=2$ & 0.14 & $\mathrm{df}=2$ & 0.13 \\
\hline H. pylori negative & Reference & & Reference & \\
\hline $\begin{array}{l}\text { H. pylori positive CagA } \\
\text { negative }\end{array}$ & 1.25 (0.58 to 2.70$)$ & 0.56 & $1.17(0.53$ to 2.55$)$ & 0.73 \\
\hline $\begin{array}{l}\text { H. pylori positive CagA } \\
\text { positive }\end{array}$ & 2.21 (0.98 to 4.98$)$ & 0.056 & 2.16 (0.94 to 4.97$)$ & 0.065 \\
\hline \multicolumn{5}{|l|}{ Smoking } \\
\hline$\geq 1$ cigarettes/day & $0.44(0.15$ to 1.27$)$ & 0.13 & $0.60(0.20$ to 1.77$)$ & 0.35 \\
\hline No smoking/other & Reference & & Reference & \\
\hline \multicolumn{5}{|l|}{ Physical activity } \\
\hline No & Reference & & Reference & \\
\hline Yes & $4.30(0.58$ to 31.87$)$ & 0.15 & 1.43 (0.58 to 3.52$)$ & 0.4 \\
\hline
\end{tabular}

${ }^{*} \mathrm{ORs}, 95 \% \mathrm{Cls}$ and $\mathrm{p}$ values obtained from bivariate logistic regression models.

†Adjusted $\mathrm{OR}, 95 \% \mathrm{Cl}$ and $\mathrm{p}$ values obtained from a multivariable logistic regression model. Adjusted for the variables in the table. Nagelkerke $R$ square $=0.089$, Hosmer and Lemeshow test; $d f=8, p=0.44$. In an additional model (not shown), an interaction term between physical activity and smoking was not significant $(p=0.9)$.

CagA, cytotoxin-associated gene A.

similar results to those obtained using the preplanned definition.

\section{DISCUSSION}

We assessed the prevalence and correlates of serological evidence of atrophic gastritis, a precursor of gastric cancer, in a general population sample of Jews and Arabs living in Jerusalem. Overall, the estimated prevalence of atrophic gastritis was 7.6\%; the prevalence was higher among Arab than Jewish participants $(8.8 \%$ vs $5.9 \%, \mathrm{p}=0.029)$.

Using serum PGs as a surrogate marker for atrophic gastritis is challenging given the lack of agreement on a specific cut-off to define atrophic gastritis and on the optimal marker. ${ }^{10}{ }^{11} 19-21$ We applied a combination of PGI level and PGI:PGII ratio, which has been shown to improve the accuracy of detection. ${ }^{22}$ When using Biohit ELISA for measuring serum PGs, a PGI level of 25-30 $\mu \mathrm{g} / \mathrm{L}$ or less and PGI: PGII $<3.0$ are commonly used cut-off values ${ }^{11}{ }^{23}$ (reviewed in ref 12), with reasonable sensitivity of $71 \%-90 \%$ and high specificity of $90 \%-98 \%$ compared with gastric biopsy. ${ }^{23-25}$ Others have shown that a higher PGI:PGII ratio of 4-6 might be warranted to enhance the sensitivity of serum PGs in identifying atrophic gastritis, ${ }^{19126}$ but at the cost of reduced specificity.
Thus, the prevalence of atrophic gastritis found in our study might be an underestimate.

A population-based study of persons aged 50-74 years in Germany ${ }^{27}$ showed a prevalence of atrophic gastritis of $6.3 \%$ with a cut-off of PGI $<25 \mu \mathrm{g} / \mathrm{L}$, and a prevalence of $5.7 \%$ using atrophic gastritis definition of PGI $<70 \mu \mathrm{g} / \mathrm{L}$; plus PGI: PGII <3.0. In Sweden, a $5.8 \%$ prevalence was documented in persons aged 35-64years, using $\mathrm{PGI}<45 \mu \mathrm{g} / \mathrm{L}$ to define atrophic gastritis, ${ }^{20}$ while in Latvia a $13.3 \%$ prevalence was found using PGI $\leq 30 \mu \mathrm{g} / \mathrm{L}$ plus PGI: PGII $<2.0$ as an indicator for advanced atrophy. ${ }^{28}$ Using a cut-off value of PGI:PGII ratio $<3$ showed a prevalence of $4.1 \%$ among persons aged 35-99 years from Iran. ${ }^{29}$ Our prevalence estimates of atrophic gastritis fall within the range of these reports, although direct comparability might be limited. The higher prevalence of atrophic gastritis found among Arab compared with Jewish participants is in line with the higher prevalence of $H$. pylori infection and exposure to CagA strains in our Arab population, as well as in our previous studies that demonstrated a higher prevalence of infection among Arabs. ${ }^{14}$ However, the excess in atrophic gastritis among Arab participants in the current study is largely attributable to the $H$. pylori seronegative category. 
Table 3 Correlates of atrophic gastritis among Arab participants

\begin{tabular}{|c|c|c|c|c|}
\hline Variable & Crude OR $(95 \% \mathrm{Cl})^{*}$ & P value* & Adjusted OR (95\% Cl)† & $\mathbf{P}$ value $†$ \\
\hline \multicolumn{5}{|l|}{ Sex } \\
\hline Males & Reference & & Reference & \\
\hline Age, years & $\mathrm{df}=2$ & $<0.001$ & $d f=2$ & 0.002 \\
\hline $25-44$ & Reference & & Reference & \\
\hline $65-78$ & 4.17 (2.03 to 8.57$)$ & $<0.001$ & 3.47 (1.61 to 7.47 ) & 0.001 \\
\hline $\begin{array}{l}\text { Helicobacter pylori lgG } \\
\text { seropositivity }\end{array}$ & $d f=2$ & $<0.001$ & $d f=2$ & $<0.001$ \\
\hline H. pylori negative & Reference & & Reference & \\
\hline H. pylori positive CagA negative & $0.18(0.11$ to 0.32$)$ & $<0.001$ & 0.18 (0.10 to 0.32$)$ & $<0.001$ \\
\hline No smoking/other & Reference & & Reference & \\
\hline \multicolumn{5}{|l|}{ Physical activity } \\
\hline No & Reference & & Reference & \\
\hline Yes & $0.46(0.28$ to 0.75$)$ & 0.002 & 0.63 (0.36 to 1.09$)$ & 0.10 \\
\hline
\end{tabular}

${ }^{*} \mathrm{OR}, 95 \% \mathrm{Cls}$ and $\mathrm{p}$ values obtained from bivariate logistic regression models.

†Adjusted $\mathrm{OR}, 95 \% \mathrm{Cl}$ and $\mathrm{p}$ values obtained from a multivariable logistic regression model. Adjusted for the variables in the table. Nagelkerke $R$ square $=0.15$, Hosmer and Lemeshow test; $d f=8, p=0.5$. In an additional model (not shown), an interaction term between physical activity and smoking was introduced; it showed a protective effect of physical activity among Arabs that appeared to be limited to non-smokers: aOR $0.52(95 \% \mathrm{Cl} 0.28$ to 0.94$)(\mathrm{p}=0.029)$, but a test for a smoking-physical activity interaction was not statistically significant $(p=0.11)$.

CagA, cytotoxin-associated gene A.

We found that only among Jewish participants, individuals infected with CagA strains had a twofold increased likelihood to have atrophic gastritis than uninfected ones. The picture among Arab participants was strikingly different: the prevalence of atrophic gastritis was considerably lower in $H$. pylori seropositive individuals than in $H$. pylori seronegative ones. This differs also from numerous reports in which a positive association between $H$. pylori infection and atrophic gastritis was demonstrated, especially in relation to CagA positive strains..$^{2023031}$

The association between $H$. pylori infection and atrophic gastritis depends on the method and cut-offs used for the detection of atrophic gastritis. ${ }^{2732}$ A meta-analysis showed strong positive associations between $H$. pylori infection and atrophic gastritis when using gastroscopy with biopsy or the PGI:PGII ratio to determine the presence of atrophic gastritis (pooled ORs of 5.7-7.2) ${ }^{32}$ However, no significant association was found when using PGI only. ${ }^{32}$ In our study, the same cut-off was applied and the same laboratory was used for both Jewish and Arab participants; yet opposing associations were found between $H$. pylori serostatus and atrophic gastritis between the two groups. Inverse associations between $H$. pylori infection and atrophic gastritis were previously reported. ${ }^{25}$ When we assessed PGI:PGII as a continuous variable, we found in both populations that the lowest mean ratio was found in persons infected with CagA strains, followed by those infected with strains lacking CagA and uninfected ones, but the trend was weaker in the Arab sample. This suggests that in those with atrophic gastritis but lacking $H$. pylori IgG antibody, the bacteria might disappear from the gastric mucosa as described elsewhere ${ }^{33}$; this could result in the disappearance of $H$. pylori serum IgG antibody.

In both populations investigated herein, the prevalence of atrophic gastritis increased with age, in agreement with other reports. ${ }^{28} 3034 \mathrm{H}$. pylori infection is acquired in childhood $^{35}$; therefore, the positive association of age and atrophic gastritis likely reflects a longer term duration of gastric inflammation in older people. Since this association was independent of $H$. pylori infection, it is possible that ageing itself also contributes to the development of atrophic gastritis. Moreover, H. pylori infection and atrophic gastritis were shown to be positively associated with accelerated epigenetic ageing, as determined by DNA methylation age in whole blood. ${ }^{36}$ This exemplifies the potential impact of atrophic gastritis and H. pylori infection on health.

One might expect that other correlates of gastric cancer, such as male sex, ${ }^{37}$ smoking $^{38}$ and physical activity ${ }^{39}$ would be related to atrophic gastritis. We found a 1.5-fold higher odds of atrophic gastritis in women than in men; this was almost identical in magnitude between 
Table 4 Population-pooled analysis of the correlates of atrophic gastritis

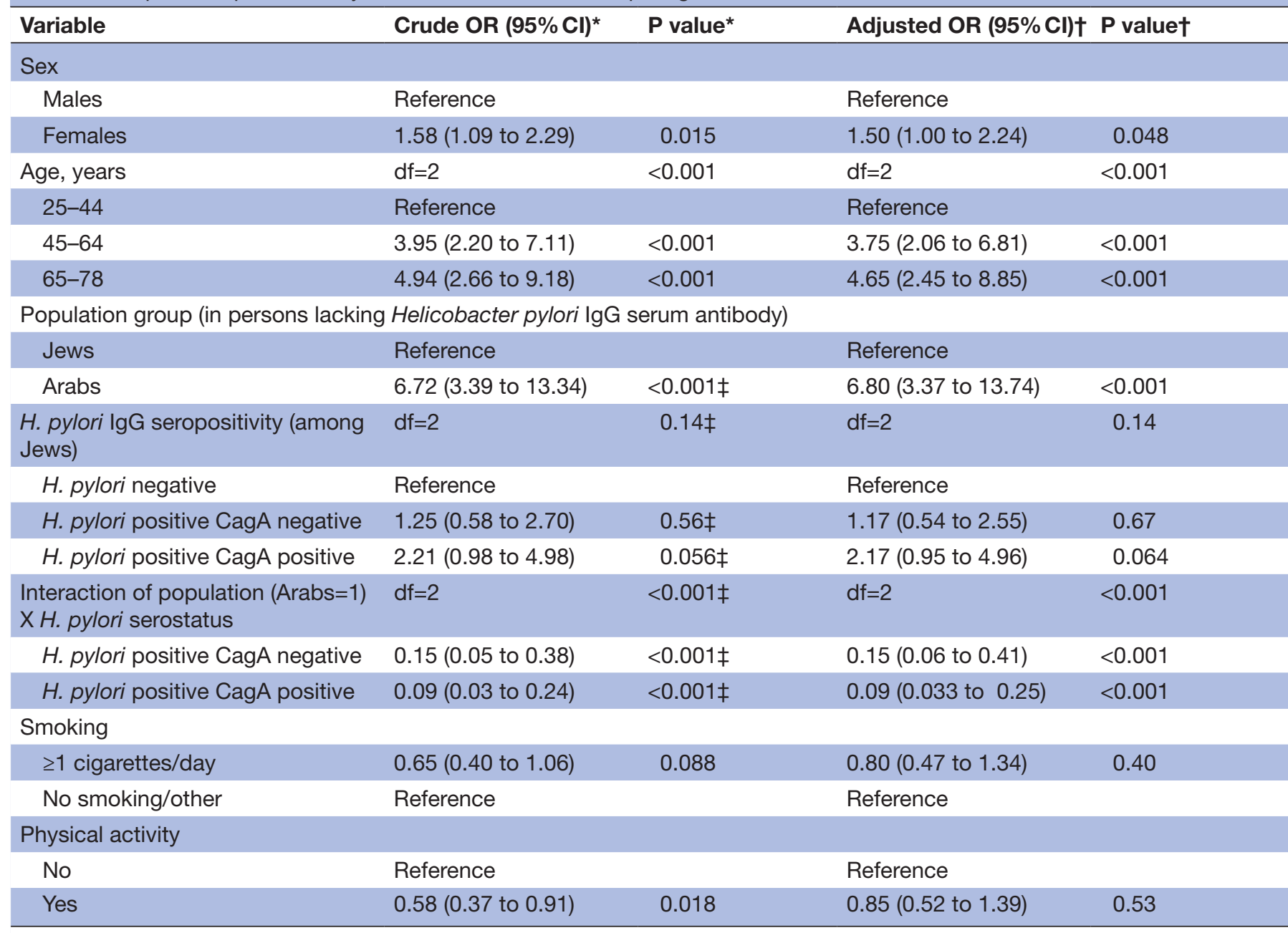

${ }^{*}$ ORs, $95 \%$ Cls and $p$ values obtained from bivariate logistic regression models.

†Adjusted $\mathrm{OR}, 95 \% \mathrm{Cl}$ and $\mathrm{p}$ values obtained from a multivariable logistic regression model that included the variables age, sex, smoking, physical activity, population group, $H$. pylori infection and an interaction term between population group and $H$. pylori infection. Nagelkerke $\mathrm{R}$ square $=0.13$, Hosmer and Lemeshow test; $\mathrm{df}=8, \mathrm{p}=0.78$.

$\ddagger$ ORs and $p$ values from a logistic regression model that included $H$. pylori infection, population group and an interaction term between population group and $H$. pylori infection.

CagA, cytotoxin-associated gene A.

Arabs and Jews. Others too have reported a higher prevalence of atrophic gastritis in women than in men. ${ }^{20} 40$ The prevalence of atrophic gastritis was lower among smokers than non-smokers in bivariate analysis $(\mathrm{p}=0.086)$, but this difference was not retained in multivariable models, confirming other reports. ${ }^{30} 340$ A systematic review ${ }^{39}$ showed that regular physical activity might be protective against gastric cancer. The borderline significant interaction in which physical activity appeared to be protective in Arabs but not in Jews provides a hint that in some populations it might confer protection. Moreover, among non-smokers of the Arab population, an inverse association with atrophic gastritis was evident, thus implying that health behaviours play a role in precancerous lesions in the stomach. This question should be further pursued, especially considering that our study was not originally powered to address it.
We found no significant association between obesity and atrophic gastritis prevalence, while mixed results were reported elsewhere. A study from Japan showed an inverse association between BMI and atrophic gastritis, ${ }^{40}$ as opposed to a positive association observed in young individuals in Sweden. ${ }^{20}$ Individuals with atrophic gastritis might experience changes in appetite and dietary habits; therefore, given the cross-sectional design of our and others' studies, ${ }^{20}{ }^{40}$ we cannot rule out the possibility of reverse causation as an explanation for discrepant findings. A large prospective study among males in Israel showed that obesity at adolescence to be positively related to increased risk of non-cardia gastric cancer. ${ }^{41}$

Our study has some limitations. First, locally validated serum PG assays are lacking, for example in comparison with histological examination of gastric biopsies. Using serum PGs to study atrophic gastritis likely underestimated 


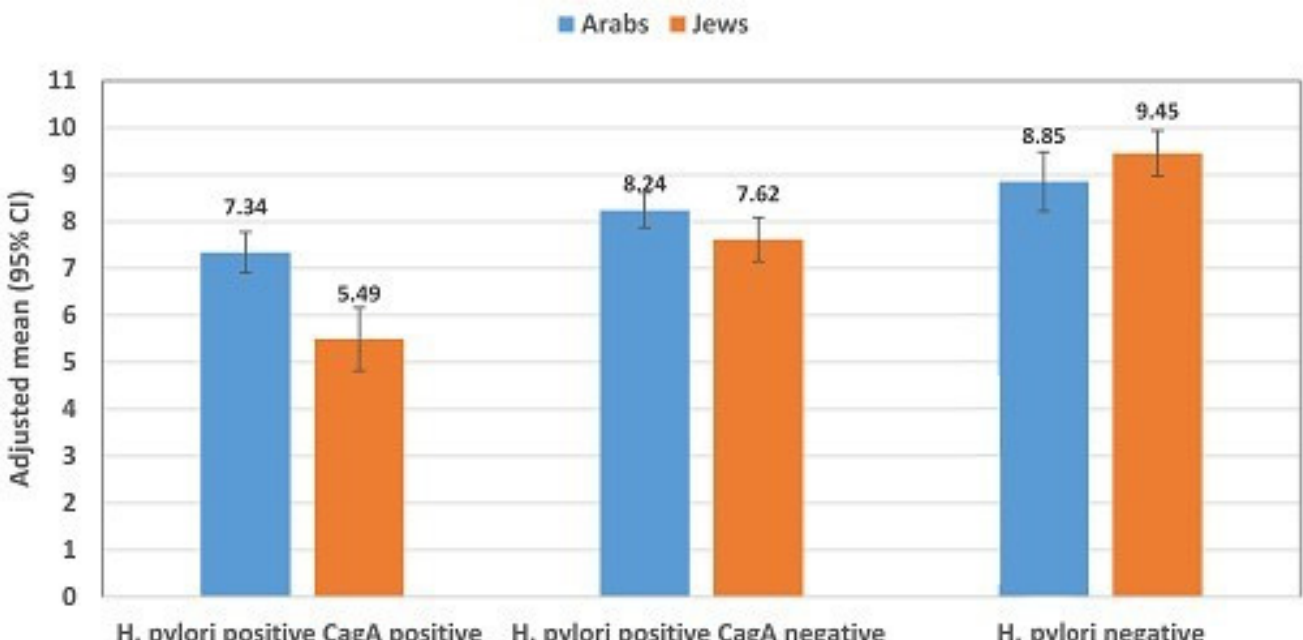

Figure 1 Age-adjusted and sex-adjusted mean PGI:PGIl ratio according to Helicobacter pylori serostatus and population group ${ }^{a}$. ${ }^{2}$ Adjusted for age and sex by a linear mixed model. Error bars represent $95 \%$ Cls. CagA, cytotoxin-associated gene A; PGI, pepsinogen I.

the prevalence of this outcome. We assume that within each population group such misclassification is not differential; thus, it would not be expected to affect the population-specific conclusions regarding the correlates of atrophic gastritis. However, eventually, we cannot rule out entirely the possibility that the validity of the assay may differ between the two populations. Second, the cross-sectional study design limits the ability to assess directionality in associations of lifestyle variables with atrophic gastritis. Some individuals may have introduced lifestyle changes because of having atrophic gastritis, thus biassing the associations towards the null. Third, data on previous $H$. pylori eradication therapy were not collected. This is due to the nature of our study, which employed anonymised archived sera and data that were collected in a previous study on cardiovascular risk factors about a decade ago. Lastly, the response rate to participate in the study was relatively low among Jewish participants (55\%). Although at enrolment, subjects were not aware of the current study hypothesis, we cannot rule out the possibility that non-response differed by atrophic gastritis or $H$. pylori infection and related characteristics.

Strengths of our study include a large general population sample with the representation of various ethnic groups and the attainment of findings of broad generalisability.

In conclusion, ethnic differences were observed in the prevalence of atrophic gastritis and in its association with $H$. pylori seropositivity. The lowest PGI:PGII ratio was observed in persons infected with CagA strains, although this measure may discriminate less well in Arabs.

\footnotetext{
Author affiliations

${ }^{1}$ Epidemiology and Preventive Medicine, Tel Aviv University Sackler Faculty of Medicine, Tel Aviv, Israel

${ }^{2}$ Braun School of Public Health and Community Medicine, Hebrew UniversityHadassah, Jerusalem, Israel

${ }^{3}$ School of Science and Health, Western Sydney University, Sydney, Australia
}

${ }^{4}$ St. Joseph Hospital, East Jerusalem and Department of Cardiology, HadassahHebrew University Medical Center, Ein Karem, Jerusalem, Israel

Acknowledgements We are very thankful to Guillermo I Perez-Perez and Martin J Blaser from New York University School of Medicine, New York City, New York, USA for providing the recombinant CagA antigen. Sadly, we would like to acknowledge the recent passing away of our mentor, colleague and friend JDK.

Contributors KM, DC, RS, HN and JDK designed the study and directed its implementation, including quality assurance and control. RS and $\mathrm{HN}$ helped supervise the field activities, data and sample collection. KM, DC and GB-D developed the laboratory protocols. GB-D performed the laboratory experiments. $\mathrm{KM}, \mathrm{DC}, \mathrm{DM}$ and JDK designed the study's analytical strategy. KM, JDK and DM analysed the data. KM and JDK prepared the first draft of the manuscript. All authors contributed to writing and approved the manuscript.

Funding Funding for this study was provided by the USAID MERC Program (Grant \# TA-MOU- 01-M21-002) (JDK-PI), by a research grant from DCURE Israel (JDKPI), the Stanley Steyer Institute for Cancer Epidemiology and Research at Tel Aviv University, School of Public Health (DC-PI), the Israel Cancer Association (KM-PI) and the Council for Higher Education- Israel (KM-PI).

Competing interests None declared.

Patient consent for publication Not required.

Ethics approval The study was approved by the Institutional Review Board of Hadassah Medical Center and by the Ethics Committee of Tel Aviv University.

Provenance and peer review Not commissioned; externally peer reviewed.

Data sharing statement Extra data are available by emailing KM at kmuhsen@ post.tau.ac.il.

Open access This is an open access article distributed in accordance with the Creative Commons Attribution Non Commercial (CC BY-NC 4.0) license, which permits others to distribute, remix, adapt, build upon this work non-commercially, and license their derivative works on different terms, provided the original work is properly cited, appropriate credit is given, any changes made indicated, and the use is non-commercial. See: http://creativecommons.org/licenses/by-nc/4.0/.

\section{REFERENCES}

1. Torre LA, Bray F, Siegel RL, et al. Global cancer statistics, 2012. CA Cancer J Clin 2015;65:87-108.

2. Lavy R, Kapiev A, Poluksht N, et al. Incidence trends and mortality rates of gastric cancer in Israel. Gastric Cancer 2013;16:121-5.

3. Plummer M, Franceschi S, Vignat J, et al. Global burden of gastric cancer attributable to Helicobacter pylori. Int J Cancer 2015;136:487-90. 
4. Webb PM, Law M, Varghese C, et al. Gastric cancer and Helicobacter pylori: a combined analysis of 12 case control studies nested within prospective cohorts. Gut 2001;49:347-53.

5. Nomura AM, Lee J, Stemmermann GN, et al. Helicobacter pylori CagA seropositivity and gastric carcinoma risk in a Japanese American population. $J$ Infect Dis 2002;186:1138-44.

6. Correa P. Gastric cancer: overview. Gastroenterol Clin North Am 2013;42:211-7.

7. Miki K, Urita Y. Using serum pepsinogens wisely in a clinical practice. J Dig Dis 2007;8:8-14.

8. Samloff IM. Cellular localization of group I pepsinogens in human gastric mucosa by immunofluorescence. Gastroenterology 1971;61:185-8.

9. Samloff IM, Liebman WM. Cellular localization of the group II pepsinogens in human stomach and duodenum by immunofluorescence. Gastroenterology 1973;65:36-42

10. Nardone G, Rocco A, Staibano S, et al. Diagnostic accuracy of the serum profile of gastric mucosa in relation to histological and morphometric diagnosis of atrophy. Aliment Pharmacol Ther 2005;22:1139-46.

11. Kekki M, Samloff IM, Varis K, et al. Serum pepsinogen I and serum gastrin in the screening of severe atrophic corpus gastritis. Scand $J$ Gastroenterol Suppl 1991:186:109-16.

12. Zagari RM, Rabitti S, Greenwood DC, et al. Systematic review with meta-analysis: diagnostic performance of the combination of pepsinogen, gastrin-17 and anti-Helicobacter pylori antibodies serum assays for the diagnosis of atrophic gastritis. Aliment Pharmacol Ther 2017;46:657-67.

13. Sipponen P, Graham DY. Importance of atrophic gastritis in diagnostics and prevention of gastric cancer: application of plasma biomarkers. Scand J Gastroenterol 2007;42:2-10.

14. Muhsen K, Cohen D, Spungin-Bialik A, et al. Seroprevalence, correlates and trends of Helicobacter pylori infection in the Israeli population. Epidemiol Infect 2012;140:1207-14.

15. Merom D, Sinnreich R, Aboudi V, et al. Lifestyle physical activity among urban Palestinians and Israelis: a cross-sectional comparison in the Palestinian-Israeli Jerusalem risk factor study. BMC Public Health 2012;12:90.

16. Kark JD, Nassar H, Shaham D, et al. Leukocyte telomere length and coronary artery calcification in Palestinians. Atherosclerosis 2013;229:363-8.

17. World Health Organization. Physical activity and adults: recommended levels of physical activity for adults aged $18-64$ years. 2016. http://www.who.int/dietphysicalactivity/factsheet adults/en/ (cited 30 Dec 2016).

18. Blaser MJ, Perez-Perez Gl, Kleanthous $\mathrm{H}$, et al. Infection with Helicobacter pylori strains possessing cagA is associated with an increased risk of developing adenocarcinoma of the stomach. Cancer Res 1995;55:2111-5.

19. Cao Q, Ran ZH, Xiao SD. Screening of atrophic gastritis and gastric cancer by serum pepsinogen, gastrin-17 and Helicobacter pylori immunoglobulin G antibodies. J Dig Dis 2007;8:15-22.

20. Song $\mathrm{H}$, Held $\mathrm{M}$, Sandin $\mathrm{S}$, et al. Increase in the prevalence of atrophic gastritis among adults age 35 to 44 years old in northern sweden between 1990 and 2009. Clin Gastroenterol Hepatol 2015;13:1592-600.

21. Graham DY, Nurgalieva ZZ, El-Zimaity HM, et al. Noninvasive versus histologic detection of gastric atrophy in a Hispanic population in North America. Clin Gastroenterol Hepatol 2006;4:306-14.

22. Dinis-Ribeiro M, da Costa-Pereira A, Lopes C, et al. Validity of serum pepsinogen $\mathrm{I} / \mathrm{II}$ ratio for the diagnosis of gastric epithelial dysplasia and intestinal metaplasia during the follow-up of patients at risk for intestinal-type gastric adenocarcinoma. Neoplasia 2004;6:449-56.

23. Storskrubb T, Aro P, Ronkainen J, et al. Serum biomarkers provide an accurate method for diagnosis of atrophic gastritis in a general population: The Kalixanda study. Scand J Gastroenterol 2008;43:1448-55.

24. Sipponen P, Ranta P, Helske T, et al. Serum levels of amidated gastrin-17 and pepsinogen I in atrophic gastritis: an observational case-control study. Scand J Gastroenterol 2002;37:785-91.

25. Väänänen $\mathrm{H}$, Vauhkonen $\mathrm{M}$, Helske $\mathrm{T}$, et al. Non-endoscopic diagnosis of atrophic gastritis with a blood test. Correlation between gastric histology and serum levels of gastrin-17 and pepsinogen I: a multicentre study. Eur J Gastroenterol Hepatol 2003;15:885-91.

26. Zhang XM, Li JX, Zhang GY, et al. The value of serum pepsinogen levels for the diagnosis of gastric diseases in Chinese Han people in midsouth China. BMC Gastroenterol 2014;14:3.

27. Brenner $H$, Rothenbacher D, Weck MN. Epidemiologic findings on serologically defined chronic atrophic gastritis strongly depend on the choice of the cutoff-value. Int J Cancer 2007;121:2782-6.

28. Leja M, Cine E, Rudzite D, et al. Prevalence of Helicobacter pylori infection and atrophic gastritis in Latvia. Eur J Gastroenterol Hepatol 2012;24:1410-7.

29. Shamsdin SA, Saberifiroozi M, Mehrabani D, et al. Pepsinogen I and II, Gastrin and Cag A Serum Levels in Shiraz. Middle East J Dig Dis 2011;3:103-9.

30. Weck MN, Stegmaier C, Rothenbacher D, et al. Epidemiology of chronic atrophic gastritis: population-based study among 9444 older adults from Germany. Aliment Pharmacol Ther 2007;26:879-87.

31. Weck MN, Gao L, Brenner H. Helicobacter pylori infection and chronic atrophic gastritis: associations according to severity of disease. Epidemiology 2009;20:569-74.

32. Weck MN, Brenner H. Association of Helicobacter pylori infection with chronic atrophic gastritis: Meta-analyses according to type of disease definition. Int J Cancer 2008;123:874-81.

33. Karnes WE, Samloff IM, Siurala M, et al. Positive serum antibody and negative tissue staining for Helicobacter pylori in subjects with atrophic body gastritis. Gastroenterology 1991;101:167-74.

34. Shibata K, Moriyama M, Fukushima T, et al. Relation of Helicobacter pylori infection and lifestyle to the risk of chronic atrophic gastritis: a cross-sectional study in Japan. J Epidemiol 2002;12:105-11.

35. Muhsen K, Jurban M, Goren S, et al. Incidence, age of acquisition and risk factors of Helicobacter pylori infection among Israeli Arab infants. J Trop Pediatr 2012;58:208-13.

36. Gao X, Zhang Y, Brenner H. Associations of Helicobacter pylori infection and chronic atrophic gastritis with accelerated epigenetic ageing in older adults. Br J Cancer 2017;117:1211-4.

37. Watabe H, Mitsushima T, Yamaji Y, et al. Predicting the development of gastric cancer from combining Helicobacter pylori antibodies and serum pepsinogen status: a prospective endoscopic cohort study. Gut 2005;54:764-8.

38. Ladeiras-Lopes R, Pereira AK, Nogueira A, et al. Smoking and gastric cancer: systematic review and meta-analysis of cohort studies. Cancer Causes Control 2008;19:689-701.

39. Abioye Al, Odesanya MO, Abioye Al, et al. Physical activity and risk of gastric cancer: a meta-analysis of observational studies. $\mathrm{Br} J$ Sports Med 2015;49:224-9.

40. Watabe H, Mitsushima T, Derakhshan MH, et al. Study of association between atrophic gastritis and body mass index: a cross-sectional study in 10,197 Japanese subjects. Dig Dis Sci 2009;54:988-95.

41. Levi Z, Kark JD, Twig G, et al. Body mass index at adolescence and risk of noncardia gastric cancer in a cohort of 1.79 million men and women. Cancer 2018;124:356-63. 